\title{
Examination on Required Cover Depth to Prevent Reinforcement Comosion Risk in Concrete
}

\author{
In-Seok Yoon \\ Dept. of Construction Info. Eng., Induk University, Choansangro 12, Nowon-gu, Seoul, Korea \\ (Received April 26, 2012; Revised October 15, 2012; Accepted October 16, 2012)
}

\begin{abstract}
In first experiment series, this paper is devoted for examining progress of reinforcement corrosion due to carbonation in concrete and to quantify uncarbonation depth to protect reinforcement from corroding. The tolerance of cover depth should be considered in order to prevent carbonation-induced corrosion. From the relationship between the weight loss of reinforcement and corrosion current density for a given time, therefore, the tolerance of cover depth to prevent carbonation-induced corrosion is computed. It is observed that corrosion occurs when the distance between carbonation front and reinforcement surface (uncarbonated depth) is smaller than $5 \mathrm{~mm}$.As a secondary purpose of this study, it is investigated to examine the interaction between carbonation and chloride penetration and their effects on concrete. This was examined experimentally under various boundary conditions. For concrete under the double condition, the risk of deterioration due to carbonation was not severe. However, it was found that the carbonation of concrete could significantly accelerate chloride penetration. As a result, chloride penetration in combination with carbonation is a serious cause of deterioration of concrete.
\end{abstract}

Keywords : carbonation, chloride penetration, reinforcement corrosion, uncarbonation depth, deterioration

\section{Introduction}

Carbonation is one of the most critical durability issues for concrete structures in urban environment. During the last decades, considerable number of studies on the carbonation of concrete has been carried out. Carbonation of concrete is the result of the interaction of $\mathrm{CO}_{2}$ gas in the atmosphere with the alkaline hydroxides in the concrete. The diffusion part of the carbonation is mainly a diffusion of a gas, carbon dioxide, in another gas. The carbon dioxide is transported into non-carbonated concrete, where a chemical reaction occurs and calcium carbonate, $\mathrm{CaCO}_{3}$, is formed. The passive layer on the reinforcement surface becomes unstable. As a result of carbonation, the pore solution $\mathrm{pH}$ (around 13.0) drops down to 9.0. ${ }^{1}$ The passive layer of reinforcement is destroyed due to the reduction of $\mathrm{pH}$. Finally the corrosion reduces the serviceability and safety performance of reinforced concrete. Thus, it is very important for concrete engineer to understand the effect of carbonation on deterioration of concrete structures.

In first experiment series, this study has two purposes.

\footnotetext{
${ }^{\dagger}$ Corresponding author: isyoon@induk.ac.kr
}

First, this study is devoted to examine the quantitative effect of carbonation of concrete on reinforcement corrosion. For this, this study mainly focuses on the quantification of corrosion product in connection with progress of carbonation. Another purpose of this study is to find when carbonation induced corrosion starts in terms of level of reinforcement. By considering the carbonation, many researchers assume that failure takes place at the moment when carbonation depth comes into contact with reinforcement. $^{2)-3)}$ However, outdoor exposure testing had different result. Nagataki et al. suggested that reinforcement corrosion started before carbonation depth meets reinforcement. ${ }^{4)}$ Thus, experiment of this study is designed to investigate the initiation time to corrosion due to carbonation of concrete. Accelerated carbonation experiment is accomplished and the effect of $\mathrm{CO}_{2}$ concentration on carbonation rate, and the properties of carbonation process with $W / C M$ ratio, and the type of concrete are examined. Also, reinforcement corrosion due to carbonation is evaluated with time. The result of this study is expected to provide us with how to optimize mixing proportion to resist carbonation and how to protect reinforcement from carbonation induced corrosion.Secondary purpose of this study is to 
investigate the interaction between carbonation and chloride penetration. The coupling between two processes is very complicated and depends on the repeating cycles of double condition. In this study, the risk of deterioration of concrete under the double condition was examined experimentally. In the experimental program, concrete samples were exposed to the following boundary conditions: (I) single deterioration, (II) deterioration of concrete contaminated with chloride, and chloride penetration in combination with carbonation. It is believed that the result leads to a new but very workable approach for designing concrete structures for long service life, taking into account the double condition.

\section{Experiment Program}

\subsection{Preparation of concrete specimens}

The natural sand had a specific gravity of 2.63 , and a unit weight of $1,830 \mathrm{~kg} / \mathrm{m}^{3}$. The fineness modulus and water absorption of the sand were 2.80 and $0.9 \%$, respectively. The coarse aggregate (crushed stone) had a specific gravity of 2.70 , a unit weight of $1,660 \mathrm{~kg} / \mathrm{m}^{3}$, a maximum aggregate size of $25 \mathrm{~mm}$, and water absorption of $0.78 \%$. Reinforcement embedded in only OPC concrete. Reinforcement was a round bar with length of 190 $\mathrm{mm}$ and diameter of $8 \mathrm{~mm}$. The exposed area of the bar was $4,770 \mathrm{~mm}^{2}$.

The mixing proportion of concrete is presented in Table 1. The slump and air content of all concrete mixtures were measured as $150 \pm 10 \mathrm{~mm}$ and $4.5 \pm 1 \%$, respectively. The concrete specimens contained four reinforcement segments (diameter of $8 \mathrm{~mm}$, exposed area of $4,770 \mathrm{~mm}^{2}$ ) with a cover depth of $12 \mathrm{~mm}$. Water curing of the specimens were carried out at $20{ }^{\circ} \mathrm{C}$ for 28 days.

\subsection{Experiment series I}

The surface of all concrete specimens was coated by gas-tight paint, leaving one end free to be exposed to $\mathrm{CO}_{2}$ gas. Two samples were taken from each mixture. Fig. 1 represents condition of accelerating experiment of carbonation and corrosion measurement. Testing program (a) is intended for examining the effect of $\mathrm{CO}_{2}$ concentration on carbonation rate of concrete.

The concrete specimens were placed in chamber with a controlled $\mathrm{CO}_{2}$ concentration of $5 \%$, at a temperature of $20{ }^{\circ} \mathrm{C}$, and a relative humidity of $65 \%$. Testing program (b) is designed for investigating reinforcement corrosion progress in connection with carbonation and the effect of water content on carbonation rate. For the effect of water content on carbonation progress, concrete specimen is ex-

Table 1. Mix proportion of concrete

\begin{tabular}{|c|c|c|c|c|c|c|c|c|}
\hline \multirow{2}{*}{ Specimen } & \multirow{2}{*}{$\begin{array}{l}\text { Air } \\
(\%)\end{array}$} & \multirow{2}{*}{$\begin{array}{c}\text { Slump } \\
(\mathrm{cm})\end{array}$} & \multirow{2}{*}{$W / C M$} & \multicolumn{5}{|c|}{ Unit weight $\left(\mathrm{kg} / \mathrm{m}^{3}\right)$} \\
\hline & & & & Water & Cement & Fly ash. & Sand & Gravel \\
\hline OPC-45 & $4.5 \pm 1.5$ & $15 \pm 1$ & 0.45 & 185 & 411 & 0 & 706 & 1001 \\
\hline OPC-50 & $4.5 \pm 1.5$ & $15 \pm 1$ & 0.50 & 185 & 370 & 0 & 720 & 1021 \\
\hline OPC-55 & $4.5 \pm 1.5$ & $15 \pm 1$ & 0.55 & 185 & 336 & 0 & 732 & 1038 \\
\hline PBC-50 & $4.5 \pm 1.5$ & $15 \pm 1$ & 0.50 & 185 & 370 & 0 & 707 & 1003 \\
\hline FA20-50 & $4.5 \pm 1.5$ & $15 \pm 1$ & 0.50 & 185 & 296 & 74 & 709 & 1006 \\
\hline TBC-50 & $4.5 \pm 1.5$ & $15 \pm 1$ & 0.50 & 185 & 296 & 74 & 700 & 993 \\
\hline
\end{tabular}

*Description of specimens:

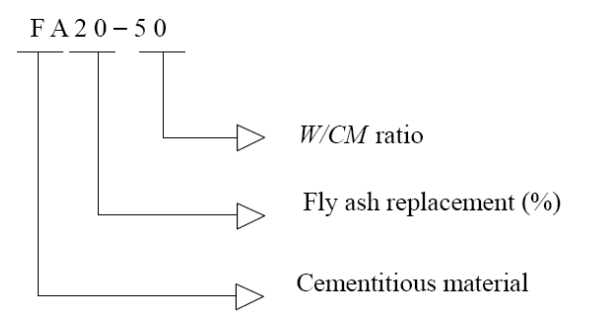

OPC: Ordinary Portland cement

PBC: Portland blastfurnace slag cement

F A: OPC + Fly ash

TBC: Ternary blended cement (PBC + Fly ash) 
posed to $\mathrm{CO}_{2} 5 \%$ environment for 3 days and then immersed in water for 3 days. Thus total 6 days is one cycle and this is continued repeatedly. Details for accelerating experiment condition are described in the Figure. For measurement of carbonation depth with elapsed time, phenolphthalein alcohol indicator was applied on the fresh fractured surfaces of the specimens.

In order to estimate reinforcement corrosion, two experimental data was obtained; weight loss of corroded reinforcement and corrosion current density. For weight loss of reinforcement due to corrosion, original weight of reinforcement $\left(\mathrm{W}_{\mathrm{o}}\right)$ was measured up to the level of $0.1 \mathrm{mg}$. After the accomplishment of the experiment, the specimens were broken by loading machine and the reinforcements were extracted. Corroded reinforcement was immersed in Clark's solution for 20 minutes and then corrosion product was eliminated in accordance with ASTM G1. ${ }^{5)}$ Finally, the weight of corroded reinforcement $\left(\mathrm{W}_{\mathrm{c}}\right)$ was measured and the amount of metal loss (ML) can be estimated as;

$$
\mathrm{ML}=\mathrm{W}_{\mathrm{o}}-\mathrm{W}_{\mathrm{c}}
$$

Meanwhile, Gecor 6 (NDT James Co. Ltd.), based on a linear polarization resistance method, was used to measure the corrosion current density $\left(\mathrm{I}_{\text {corr }}\right)$ of reinforcement. This value has a limitation as an instant data at measurement time.

\subsection{Experiment series II}

Various exposure conditions of concrete are designed as shown in Fig. 1. In the first series of experiment, concrete specimens were placed in accelerating carbonation chamber with $5 \%$ of $\mathrm{CO}_{2}, 20{ }^{\circ} \mathrm{C}$ of temperature, and 65 $\%$ of relative humidity. Meanwhile, concrete was immersed into the solution of $0.5 \mathrm{M} \mathrm{NaCl}$. This was simulated for depicting submerged zone and tidal zone of marine concrete structures. In the second series, when concrete was mixed, that were added with $\mathrm{NaCl}$ of $1.2 \mathrm{~kg} / \mathrm{m}^{3}$, which was proposed as a critical chloride content by JSCE Code. ${ }^{\text {) }}$ The specimens were exposed to accelerating carbonation chamber continuously. In the third series, concrete were placed in accelerating carbonation chamber for 3 days, and then immersed into $0.5 \mathrm{M} \mathrm{NaCl}$ solution for next 3 days. In order to simulate a tidal zone of marine concrete, the exposure time ratio of carbonation to chloride penetration was controlled as a one vs. one.

The phenolphthalein indicator was applied on the fresh fracture of the specimens to assess carbonation depth. And the free chloride content and total chloride content in the concrete were measured with depth.

\section{Results and Discussion}

\subsection{Expeniment series I : Carbonation Progress of concrete and reinforcement conosion}

The natural carbonation process in concrete has an evolution measurable in years. In the conventional approach to the carbonation phenomenon, empirical formulae are generally used for its prediction. These equations have originated from the assumption that carbonation would progress in proportion to exposure time as; ${ }^{7}$

$$
X_{c}=A \cdot t^{n}
$$

in which, $X_{c}$ is the carbonation depth, $\mathrm{A}$ is the carbonation rate coefficient, $t$ is the exposure time, $n$ is 0.5 normally.

Fig. 2 (a) shows the carbonation progress of OPC concrete with $W / C M$ ratio. The figure represents the very considerable influence of $W / C M$ ratio on carbonation. Generally, the fundamental factor to determine the rate of carbonation is the diffusivity of the hardened cement paste. The diffusivity is a function of the pore system of the hardened
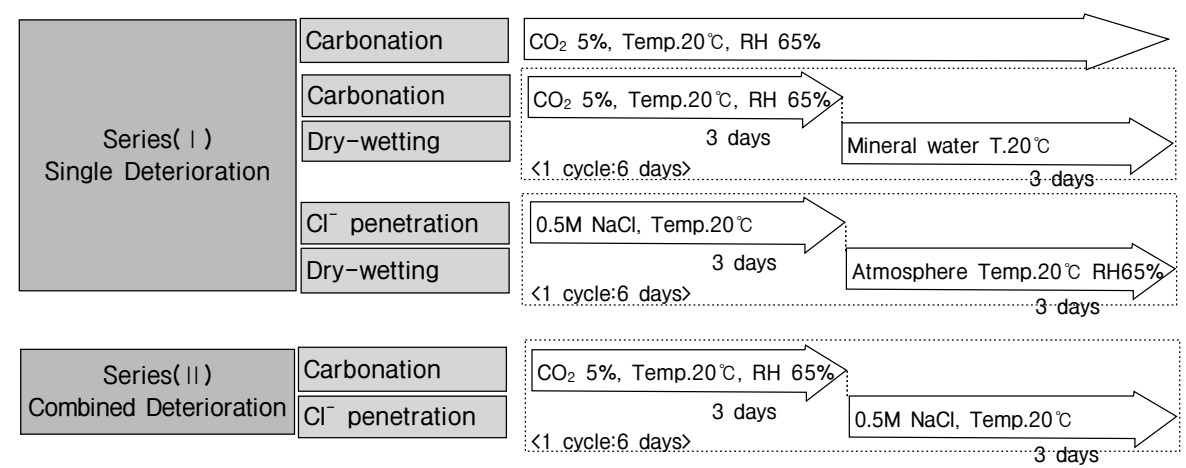

Fig. 1. Experiment series. 
cement paste when the diffusion of $\mathrm{CO}_{2}$ takes place. For this reason, concrete with high $W / C M$ ratio has a high $\mathrm{CO}_{2}$ diffusivity, thus, existed concrete structures with high $W / C M$ ratio is needed to acquire the intended long-term service life of concrete structures. Also, the type of cement is a main factor controlling carbonation in Fig. 2 (b). Overall, OPC concrete has a slow rate of carbonation in comparison with blended concrete because it contains high $\mathrm{CaO}$ content. The rate of carbonation for blended concrete increases because the pozzolanic reaction of fly ash and the dormant hydraulicity of slag in blended cement pastes reduce the amount of $\mathrm{Ca}(\mathrm{OH})_{2}$. Especially, it should be

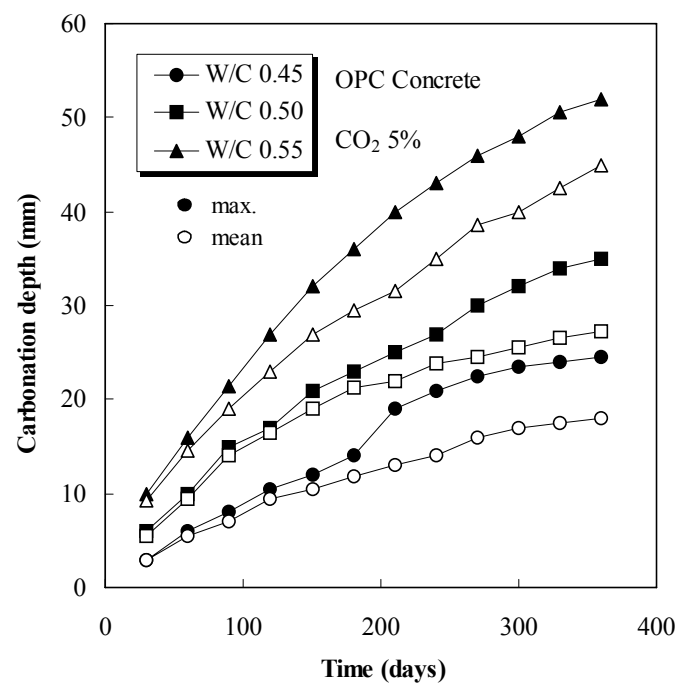

(a) OPC concrete

Fig. 2. Carbonation depth of concrete.

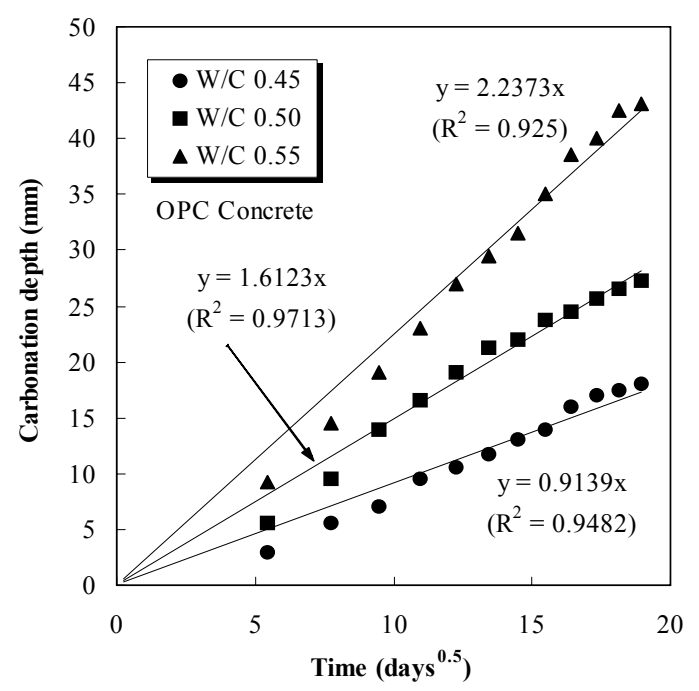

(a) OPC concrete

Fig. 3. Carbonation rate of concrete vs. time. noted that the rate of carbonation for ternary blended concrete containing both granulated blast furnace slag and fly ash increases very much. According to Ho\&Lewis, with further curing to 90 days, concrete containing fly ash showed a slower rate of carbonation when compared to OPC concrete. ${ }^{8)}$ Thus, curing duration of binary blended concrete or ternary blended concrete is more required in comparison with that of OPC concrete.

Fig. 3 shows carbonation rate coefficient $(K)$ with $W / C M$ ratio and type of concrete in the accelerating carbonation and it is regulated in Table 2 .

Pore structure of concrete elements tends to be saturated

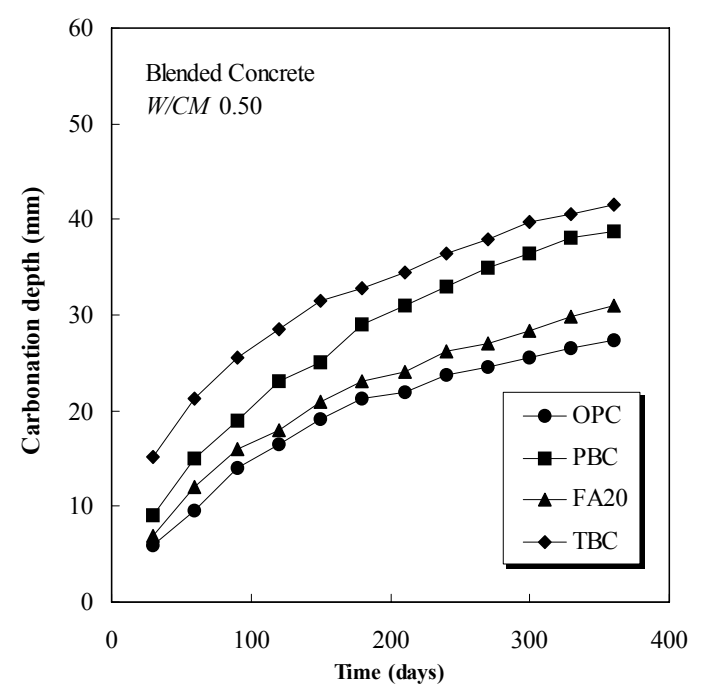

(b) Blended concrete

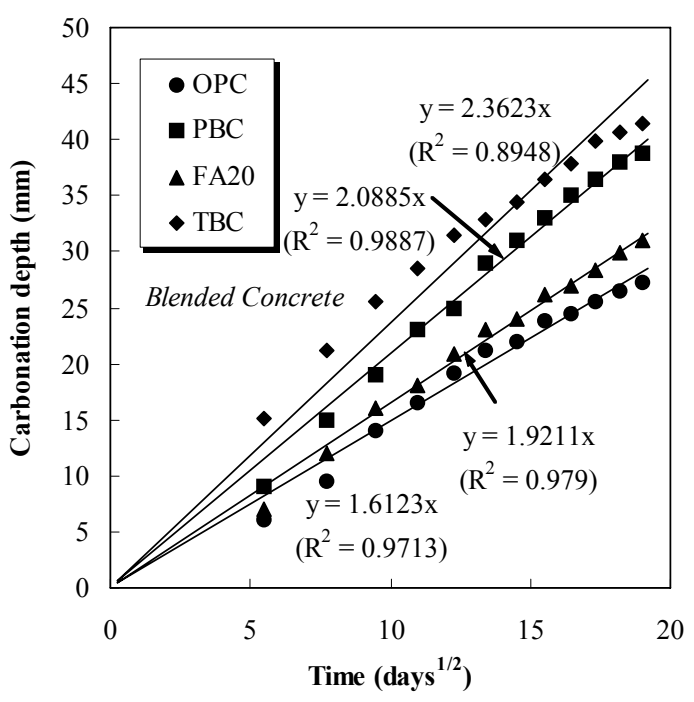

(b) Blended concrete 
or dried out by environmental factors in random periods throughout their lifetime. Arguably, these wetting-drying cycles affect the penetration of atmospheric $\mathrm{CO}_{2}$ into the concrete. For older concrete structures, measured carbonation depth was less than predicted, because $\mathrm{CO}_{2}$ diffusion can be hindered by rain with elapsed time because of pore blocking of water in concrete skin. Actually, the in-situ investigations of reinforced concrete structures in an industrial area along the Arabian Gulf showed that the carbonation depth in sheltered outdoors concrete structures equaled $15 \mathrm{~mm}$, while it was $3 \sim 5 \mathrm{~mm}$ for unsheltered outdoors concrete structures. ${ }^{9)}$ For this reason, a traditional time function $X_{c}=t^{n}$ with $n<0.5$ was proposed in RILEM. $^{10)}$

In addition, Papadakis et al., ${ }^{11)} \mathrm{CEB},{ }^{12)}$ and Houst et $a{ }^{13)}$ expressed that effective $\mathrm{CO}_{2}$ diffusivity has a function of $(1-\mathrm{RH} / 100)^{\mathrm{m}}$.

$$
D_{\mathrm{CO}_{2}} \propto(1-\mathrm{RH} / 100)^{m}
$$

Water in concrete blocks pores and thus hinders the diffusion of $\mathrm{CO}_{2}$ through the pores while providing a medium for reaction between $\mathrm{CO}_{2}$ and $\mathrm{Ca}(\mathrm{OH})_{2}$. In this throughsolution process, $\mathrm{CO}_{2}$ gas dissolves in $\mathrm{Ca}(\mathrm{OH})_{2}$ in conditions in which an adequate amount of water exists in the pores. Thus, a R.H. of approximately $50 \%$ to $70 \%$ is the most suitable condition for the chemical progress of carbonation in concrete. ${ }^{14)}$ It is then inferred that Eq.(3) can be valid if R.H. is higher than $50 \%$.

Fig. 4 shows the effect of water on the carbonation of concrete. The accelerated experiment is accomplished in order to compare experiment of carbonation with repeating carbonation for a week and water immersion for a week. An exposed time of $\mathrm{CO}_{2}$ in the experimental program repeating carbonation and water immersion is half compared with that of $\mathrm{CO}_{2}$ in the experimental program continuing carbonation. The carbonation depth of concrete in experimental program repeating carbonation and water immersion would be half time relative to that of concrete in experimental program continuing carbonation, however, it is below half time in fact. The reason would be that the microstructure of concrete develops with time gradually because the degree of hydration of concrete increases for the time of water immersion.

Fig. 5 represents corrosion current density of reinforcement. Corrosion current density of reinforcement tends to be high, increasing $W / C M$ ratio. Therefore, it is obvious that reinforcement corrosion is governed by degree of carbonation.

Another point is a corrosion current density of rein-

Table 2. Carbonation rate coefficient with type of concrete

\begin{tabular}{ccccccc}
\hline Con'c specimen & OPC-45 & OPC-50 & OPC-55 & PBC-50 & FA20-50 & TBC-50 \\
\hline $\mathrm{K}(\mathrm{mm} / \sqrt{\text { day }})$ & 0.9139 & 1.6123 & 2.2373 & 2.0885 & 1.9211 & 2.3623 \\
\hline
\end{tabular}

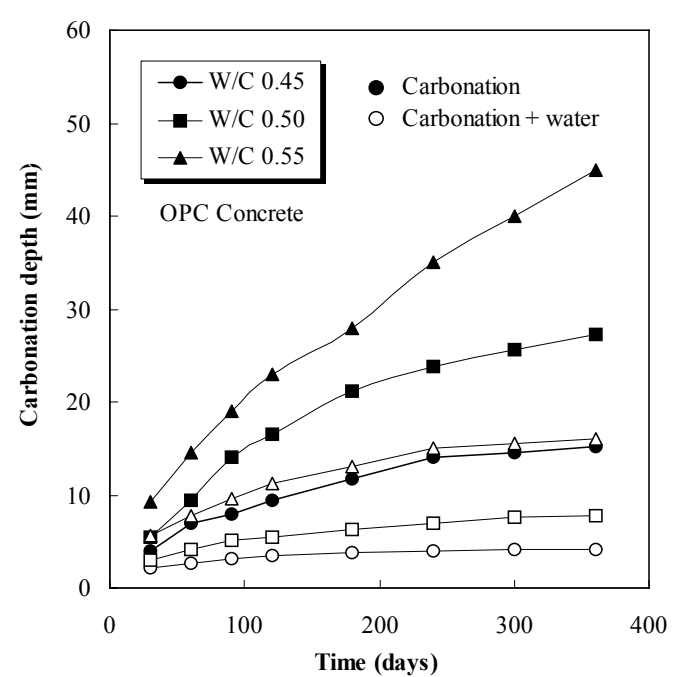

(a) OPC concrete

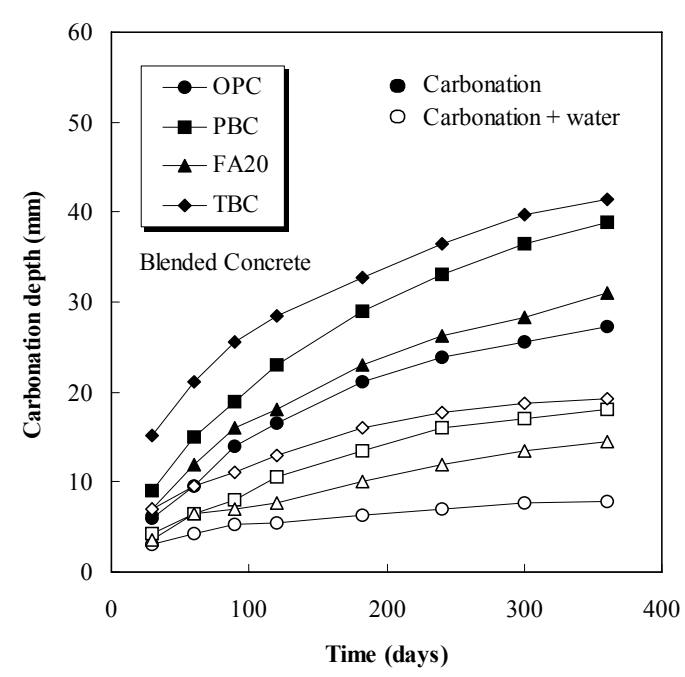

(b) Blended concrete

Fig. 4. Effect of water on carbonation of concrete. 


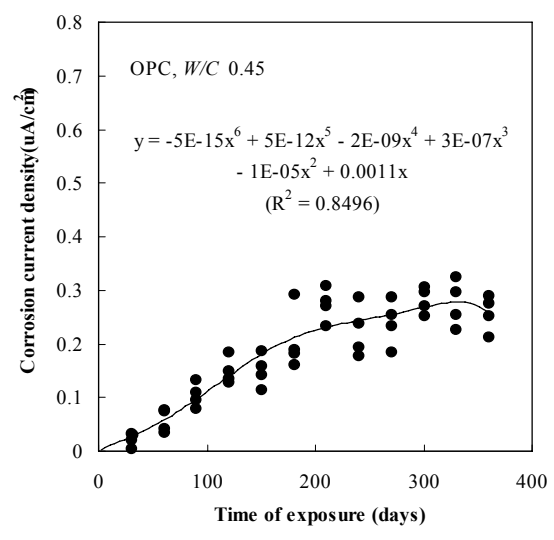

(a) OPC, $W / C M 0.45$

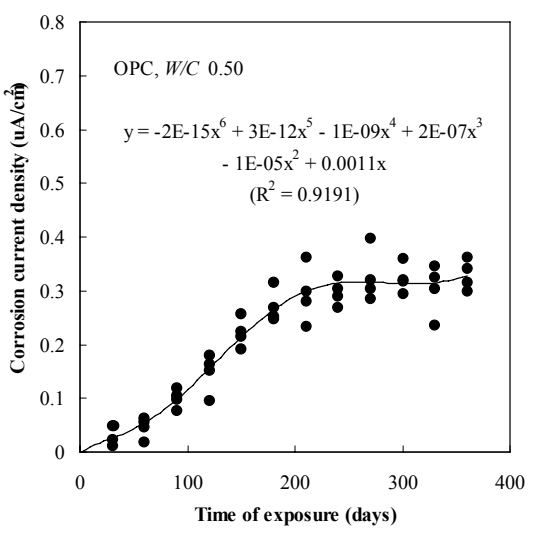

(b)OPC, $W / C M 0.50$

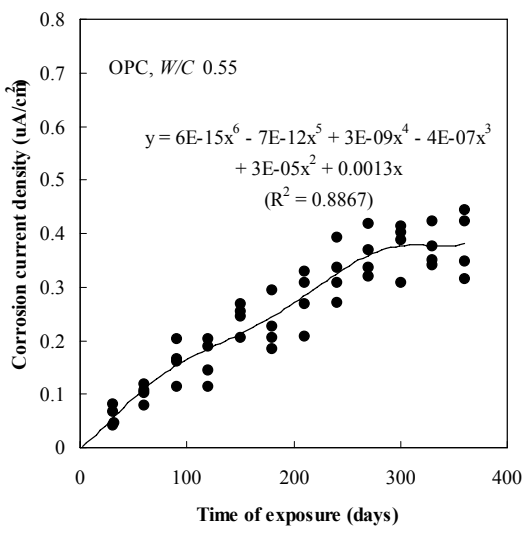

(c) $\mathrm{OPC}, W / C M 0.55$

Fig. 5. Corrosion current density of reinforcement with elapsed time.

forcement. Although carbonation depth surpassed cover depth for all concrete after around 200 days, the corrosion current density of reinforcement did not exceed $0.5 \mathrm{uA} / \mathrm{cm}^{2}$ until ending of experiment. This is very different with corrosion rate associated with chloride attack. Broomfield suggested that chloride attack can give corrosion rates of more than $1.0 \mathrm{uA} / \mathrm{cm}^{215)}$ This may be due to the fact that carbonated concrete is prone to dry out and testing is normally done in the dry.

As a rule of thumb, reinforcement corrosion begins if the carbonation depth reaches the level of reinforcement and when the $\mathrm{pH}$ of the location drops dramatically. In fact, investigations showed that carbonation-induced corrosion starts slightly before carbonation depth reaches the level of reinforcement. It was reported that reinforcement corrosion begins when so-called "the uncarbonation depth" (see Fig. 6) of the concrete equals about $8 \mathrm{~mm}$ without

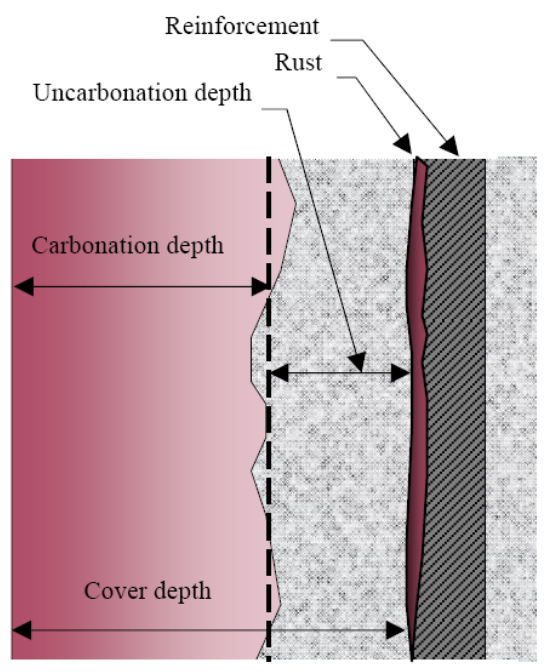

Fig. 6. Schematic diagram of uncarbonation depth. presence of chloride ions. The uncarbonation depth denotes the distance between the carbonation front and the surface of reinforcement bar.. This value becomes $20 \mathrm{~mm}$ for the concrete structures containing chloride ions. ${ }^{16}$ These findings often result into ambiguity of interpretation. One of the explanations for this phenomenon could be the fact that carbonation depth measured by the phenolphthalein indicator could usually be highlighted in the range of $\mathrm{pH} 8.3 \sim 9.5$, while reinforcement corrosion is triggered within the range of $\mathrm{pH} 11.0 \sim 11.5$.

In this study, the corrosion current density and metal loss in the reinforcement were measured to determine the uncarbonation depth from inter-relationship. Fig. 7 presents schematic diagram to the relationship. Based on the Faraday's law, the measured quantity of weight loss after testing can be transferred into a rate of section loss $\left(\Delta A_{c}\right)$ by Eq. (4).

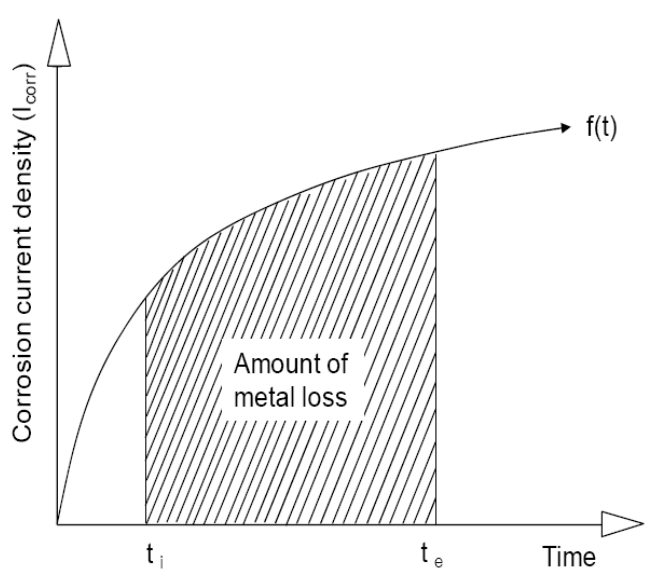

Fig. 7. Schematic concept to define the relationship between corrosion current density and metal loss. 
Table 3. Determination of uncarbonation depth

\begin{tabular}{cccc}
\hline W/CM ratio & $\begin{array}{c}\text { Weight loss } \\
\text { (mg) }\end{array}$ & $\begin{array}{c}\text { Time to orrosion } \\
\text { (days) }\end{array}$ & $\begin{array}{c}\text { Uncarbonation } \\
\text { depth (mm) }\end{array}$ \\
\hline 0.45 & 219.5 & 155 & 1 \\
0.50 & 384.7 & 75 & -1 \\
0.55 & 534.3 & 18 & 5 \\
\hline
\end{tabular}

$$
\Delta A_{c}(u \mathrm{~m} / \text { year })=\frac{M L}{A \cdot t \cdot \rho \cdot 10^{4}}
$$

where,

$M L$ : a weight loss of reinforcement (mg),

$A$ : a surface area of reinforement $\left(\mathrm{cm}^{2}\right)$,

$t$ : testing time (years),

$\rho:$ a density of reinforement $\left(=7,580 \mathrm{mg} / \mathrm{cm}^{3}\right)$,

The equation can be written as

$$
M L=6,826,087 A \int_{t_{i}}^{t_{e}} I_{c o r r}(t) d t
$$

where,

$t_{e}$ : time to expire testing,

$t_{i}$ : initiation time to corrosion.

From the relationship between the weight loss of reinforcement and corrosion current density for a given time, the initiation time for corrosion is computed through the inversion of the solution of Eq. (19). Table 3 summarizes the result. For safety, JSCE suggested that the uncarbonation depth should be more than $10 \mathrm{~mm}$. In this study, however, reinforcement corrosion was found to occur when the uncarbonation depth equaled a maximum of 5 mm. ${ }^{17)}$ The result is somewhat lower than the suggestion of JSCE. Current investigation results indicate that the concrete structures would not face a severe risk due to carbonation if the uncarbonation depth is higher than 5 $\mathrm{mm}$ to $10 \mathrm{~mm}$. The uncarbonation depth should be considered when using phenolphthalein indicator measured carbonation depth to determine rate and extent of depassivation. Based on this study, more systematic approaches is needed to protect reinforcement from corroding in terms of designing of cover depth.

\subsection{Experiment series II : Combined deterioration}

Fig. 8 shows chloride profiles of concrete under the single deterioration and the double deterioration after one year. For carbonated concrete, the chloride profiles do not fit with the Fickian behavior. These profiles are usually attributed to a chloride adsorption-desorption reaction due to the effect of carbonation and the washing effect of water. Reinforcement corrosion might be initiated before the carbonation depth reaches up to the level of reinforcement. This is especially obvious in concrete with a high $W / C M$ ratio. The comparison of double deterioration and single deterioration (drying-wetting cycle) should be examined. The chloride content in the double condition and the single condition matches each other after certain depth. For concrete with $W / C M$ ratio of $0.45,0.50$, the matching occurs at depth of $21 \mathrm{~mm}, 23 \mathrm{~mm}$, respectively. The reason for this is that physico-chemical adsorbed chloride ions are set free with the advance of carbonation. ${ }^{18)}$ That is, chloride has impact on reinforcement corrosion up to depth of $21 \mathrm{~mm}$ to $23 \mathrm{~mm}$ from the carbonation depth. This means that the amount of desorbed chloride ions in carbonated concrete re-diffuses into uncarbonated concrete and this influences the behavior of

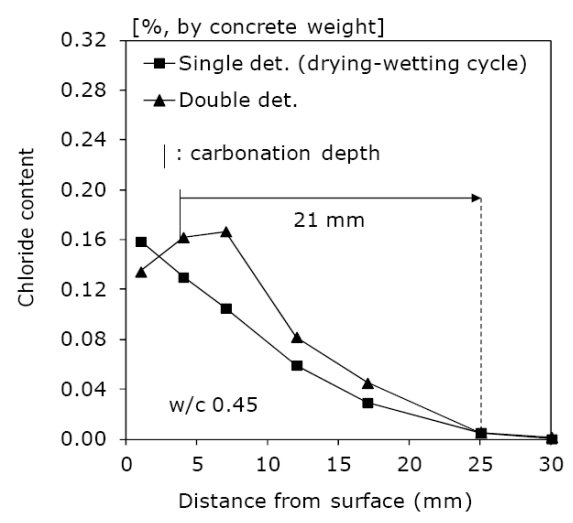

(a) OPC, $W / C M 0.45$

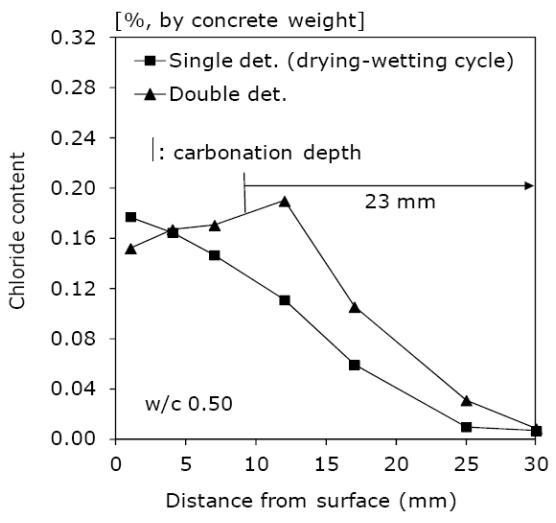

(b) OPC, $W / C M 0.50$

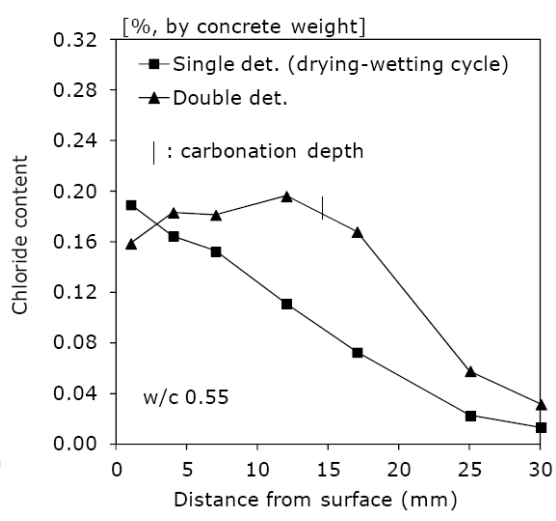

(c) $\mathrm{OPC}, W / C M 0.55$

Fig. 8. Total chloride profile of concrete exposed to various exposure conditions (1 year). 
Table 4. Depth influenced by chloride enrichment from carbonation depth

\begin{tabular}{l|c|c|c}
\hline Double condition & 0.45 & 0.50 & 0.55 \\
\hline $\begin{array}{l}\text { Carbonation + contamination } \\
\text { of chloride }\end{array}$ & $6.5 \mathrm{~mm}$ & $9.0 \mathrm{~mm}$ & $7.0 \mathrm{~mm}$ \\
\hline $\begin{array}{l}\text { Chloride penetration in } \\
\text { combination with carbonation }\end{array}$ & $21.0 \mathrm{~mm}$ & $23.0 \mathrm{~mm}$ & - \\
\hline
\end{tabular}

chloride penetration up to $21 \mathrm{~mm}$ to $23 \mathrm{~mm}$ from the carbonation depth immediately. This interaction between carbonation and chloride contamination of concrete is likely to be a cause of the most severe problem encountered in practice. $^{19)}$

The rate of carbonation of concrete under the combined condition is found to be much slower than that of concrete under the single condition. It is concluded that the carbonation of concrete is not a main cause of deterioration of concrete under the double condition. However, the carbonation of concrete has a significant impact on chloride penetration. For concrete contaminated with chloride at mixing stage, chloride enrichment due to carbonation have an influence on the durability performance of concrete up to depth of $6.5 \mathrm{~mm}$ to $7.0 \mathrm{~mm}$ from the carbonation depth. This value increases for concrete attacked by chloride in combination with carbonation (Table 4). In this case, chloride enrichment due to carbonation can affect the chloride profile up to $21 \mathrm{~mm}$ to $23 \mathrm{~mm}$ from the carbonation depth.

\section{Conclusions}

1) It was observed that based upon increasing $\mathrm{CO}_{2}$ concentration, carbonation progress of concrete with high $W / C M$ ratio is faster than that of concrete with low $W / C M$ ratio. Water content was also examined in terms of carbonation rate of concrete.

2) The reinforcement corrosion was started when the uncarbonation depth was maximum $5 \mathrm{~mm}$. In order to satisfy aimed service life of concrete structures exposed to $\mathrm{CO}_{2}$ concentration, uncarbonation depth $5 \mathrm{~mm}$ must be considered at computation of required cover depth.

3) In combined deterioration, chloride enrichment due to carbonation can affect the chloride profile up to $21 \mathrm{~mm}$ to $23 \mathrm{~mm}$ from the carbonation depth. The conclusions show that these depths influenced by the double deterioration should be taken into account for designing cover depth in terms of the carbonation of concrete. For further research, it is necessary to predict the chloride profile of concrete under the double condition.

\section{Acknowledgement}

This research was sponsored by Induk University, Korea.

\section{References}

1. J. P. Broomfield, Corrosion of Steel in Concrete, $2^{\text {nd }}$ Edition, London, 78 (1997).

2. Y. F. Houst, P. E. Roelfstra, and F. H. Wittman, Proc. Int. Col. on Mat. Sci. and Restoration, RILEM, 235 (1983).

3. S. Kang, S. Hong, and M. Kim, Corros. and Protect, 3 (2004).

4. S. Nagataki, H. Ohga, and E. K. Kim, ACI SP 91-24, 342 (1996).

5. ASTM G1-72, 440 (1979).

6. JSCE, Concrete Standard Specification (in Japanese), Part of Durability, 221 (1999)

7. The Report of the JCI Committee on Carbonation, Japan Concrete Institute, 105 (1993)

8. D. W. S. Ho and R. K. Lewis, ACI, Detroit, USA (1983).

9. S. E. Hussain, I. S. Paul, and H. M. Ruthaiyea, Evaluations and Repair Strategies for Shallow Foundations, Proceedings of 6th Middle East Corrosion Conference, Haifai, Israel (1994).

10. RILEM REPORT 12, Performance Criteria for Concrete Durability, E \& FN SPON, 98 (1995).

11. V. G. Papadakis, C. G. Vayenas, and M. N. Fardis, ACI Materials Journal, 88, 2 (1991).

12. CEB Bulletin d'Information No 238, New Approach to Durability Design (1997).

13. Y. F. Houst and F. H. Wittmann, Cement and Concr Res., 32, 28 (2002).

14. A. Müller and G. Sickert, Concrete Precasting Plant and Technology 11, Chapman Hall (1995)

15. J. P. Broomfield, J. Rodriguez, L. M. Ortega, and A. M. Garcia, ACI Special Publication 151 (1994).

16. K. Kishitani, K. Kobayashi, N. Kashino, and Y. Uno, Concr Res Tech, 2, 77 (1991).

17. Concrete Standard Specification, Part of Durability, JSCE (1999).

18. K. Kobayashi, R. Siraki, and K. Kawai, Concr Res and Tech, 1, 2 (1990)

19. RILEM Report Technical Committee 60-CSC, P. Schieß1 (Eds.), E \& FN SPON (1988). 